\title{
Evaluation of increased vitamin D fortification in high-temperature, short-time-processed $2 \%$ milk, UHT-processed $2 \%$ fat chocolate milk, and low-fat strawberry yogurt
}

\author{
A. L. Hanson* and L. E. Metzgert ${ }^{1}$ \\ *Midwest Dairy Food Research Center, Food Science \& Nutrition Department, University of Minnesota, St. Paul 55108 \\ †Midwest Dairy Food Research Center, Dairy Science Department, South Dakota State University, Dairy-Micro Building, SDM 314, Brookings \\ 57007
}

\begin{abstract}
The objective of this study was to determine the effect of increased vitamin D fortification $(250 \mathrm{IU} /$ serving) of high-temperature, short-time (HTST)-processed $2 \%$ fat milk, UHT-processed $2 \%$ fat chocolate milk, and low-fat strawberry yogurt on the sensory characteristics and stability of vitamin D during processing and storage. Three replicates of HTST pasteurized $2 \%$ fat milk, UHT pasteurized $2 \%$ fat chocolate milk, and low-fat strawberry yogurt were manufactured. Each of the 3 replicates for all products contained a control (no vitamin D fortification), a treatment group with 100 IU vitamin $\mathrm{D} /$ serving (current level of vitamin D fortification), and a treatment group with $250 \mathrm{IU}$ vitamin $\mathrm{D}$ /serving. A cold-water dispersible vitamin $\mathrm{D}_{3}$ concentrate was used for all fortifications. The HTSTprocessed $2 \%$ fat milk was stored for $21 \mathrm{~d}$, with vitamin $\mathrm{D}$ analysis done before processing and on $\mathrm{d} 0,14$, and 21 . Sensory analysis was conducted on d 14 . The UHTprocessed $2 \%$ fat chocolate milk was stored for $60 \mathrm{~d}$, with vitamin $\mathrm{D}$ analysis done before processing and on d 0, 40, and 60. Sensory analysis was conducted on d 40. Low-fat strawberry yogurt was stored for $42 \mathrm{~d}$, with vitamin $\mathrm{D}$ analysis done before processing, and on $\mathrm{d} 0$, 28 , and 42. Sensory analysis was conducted on d 28 . Vitamin D levels in the fortified products were found to be similar to the target levels of fortification (100 and 250 IU vitamin D per serving) for all products, indicating no loss of vitamin D during processing. Vitamin D was also found to be stable over the shelf life of each product. Increasing the fortification of vitamin $\mathrm{D}$ from 100 to $250 \mathrm{IU} /$ serving did not result in a change in the sensory characteristics of HTST-processed $2 \%$ fat milk, UHT-processed $2 \%$ fat chocolate milk, or low-fat strawberry yogurt. These results indicate that it is feasible to
\end{abstract}

Received September 2, 2009.

Accepted October 31, 2009.

${ }^{1}$ Corresponding author: Lloyd.Metzger@sdstate.edu increase vitamin D fortification from 100 to $250 \mathrm{IU}$ per serving in these products.

Key words: vitamin D, stability, fortification, dairy product

\section{INTRODUCTION}

Vitamin D is necessary for proper skeletal development and plays a fundamental role in regulating serum calcium and phosphorus concentrations in the body. Vitamin D is not technically classified as an essential nutrient in the body because it can be photosynthesized in the skin as a result of exposure to solar UVB radiation (Holick, 1994). However, at latitudes above $40^{\circ} \mathrm{N}$ or below $40^{\circ} \mathrm{S}$, no photosynthesized vitamin $\mathrm{D}$ is produced in the skin for several months of the year, and supplementation of vitamin D is required to prevent deficiency (Webb et al., 1988; Ladizesky et al., 1995). Additionally, use of sunscreen can limit the amount of vitamin D produced in the skin from sun exposure (Hollis, 2005). Determining the recommendation for adequate intake of vitamin $\mathrm{D}$ is difficult because most studies are confounded by several factors related to vitamin $\mathrm{D}$ production in the skin.

The first recommended dietary allowance for vitamin D in the United States was established in 1941 and set at $400 \mathrm{IU}$ for adults. The value of $400 \mathrm{IU}$ was determined based on a teaspoon of cod liver oil, which was found to be capable of preventing rickets (Park, 1940). Dietary recommendations have changed substantially since the 1940s and currently the term "dietary reference intakes" is used to collectively describe 4 terms including estimated average requirement (EAR), recommended dietary allowance (RDA), adequate intake (AI), and tolerable upper intake level (UL; National Academy of Sciences, 1997). The purpose of the RDA is to serve as a goal for daily intake of individuals. The RDA is calculated from the EAR and is equal to the EAR plus 2 standard deviations of the EAR. The EAR is the daily intake value that is estimated to meet the requirements of $50 \%$ of the individuals in a spe- 
cific group. However, in the case of vitamin D there is not sufficient scientific evidence available to determine an EAR. Consequently, the AI is used instead of the RDA. The AI is determined based on experimentally determined intake levels or approximations of observed mean nutrient intakes by a group of healthy people. As further research is conducted, it may be possible to replace AI estimates with EARs and RDAs.

Vitamin D deficiency contributes to diseases such as childhood rickets, osteoporosis, and osteomalacia, and being deficient in vitamin $\mathrm{D}$ has been shown to increase the risk of developing cancers, osteoporotic fractures, and autoimmune diseases (Holick, 2002). It is estimated that a significant portion $(30-40 \%)$ of the US population is deficient in vitamin $\mathrm{D}$ (Thomas et al., 1998). Additionally, publications on vitamin D deficiency have suggested that the recommended adequate intake of vitamin D is too low and should be increased to at least 800 IU for adults (Holick, 2007; Brannon et al., 2008). However, the potential for vitamin D intoxication also needs to be considered when contemplating an increase in the AI of vitamin D. Toxicity levels have been shown to be substantially higher than originally estimated, and Vieth (1999) has shown no adverse effects at supplementation levels 2 times the current recommended intake. Additionally, Heaney et al. (2003) showed no adverse effects at a level of 10,000 IU per day for a period of 5 mo. Consequently, vitamin $\mathrm{D}$ intoxication as a result of an increase in the AI of vitamin $\mathrm{D}$ does not appear to be a major concern and an increase in the AI of vitamin D to at least $800 \mathrm{IU}$ is expected.

In the United States, all forms of fluid milk are currently fortified with 100 IU of vitamin D per serving $(240 \mathrm{~mL})$. Milk has been fortified with vitamin D for more than $50 \mathrm{yr}$, and fluid milk is generally the main medium of vitamin D fortification in the United States. However, the per capita consumption of fluid white milk in the United States has steadily declined in the last 50 yr (International Dairy Foods Association, 2008). Consequently, the level of dietary vitamin D in the US diet provided by fluid milk has declined, and targeted supplementation of high-risk groups, as well as fortification of a larger variety of products with vitamin $\mathrm{D}$, has been recommended (Calvo and Whiting, 2003).

In contrast to the declining consumption of fluid milk, consumption of flavored milk drinks and yogurt has increased substantially in the last $20 \mathrm{yr}$; these products had a per capita consumption of 6.59 and 5.23 kg, respectively, in 2007 (International Dairy Foods Association, 2008). Consequently, utilization of flavored milk drinks and yogurt as additional mediums for supplying vitamin $\mathrm{D}$ to consumers can compensate for a reduction in the consumption of white milk. During yogurt and flavored milk manufacture, the milk base is processed in a manner similar to that used for fluid milk. Consequently, the fortification techniques used for fluid milk (FDA, 2007) can also be used in flavored milk and yogurt manufacture.

Several studies have been conducted on the stability of vitamin D in milk and other dairy products (Renken and Warthesen, 1993; Upreti et al., 2002; Kazmi et al., 2007; Wagner et al., 2008). These studies have all indicated that vitamin $\mathrm{D}$ is stable during processing and storage. However, these studies evaluated vitamin D stability at the current fortification level (100 IU/serving) or did not include sensory analysis to determine if vitamin D fortification had an effect on the sensory characteristics of dairy products. Because an increase in the fortification level of vitamin D has been suggested, the effect of an increased fortification level on vitamin D stability and sensory characteristics is warranted. The objective of this study was to determine the effect of increased vitamin D fortification (250 IU/serving) of HTST-processed $2 \%$ fat milk, UHT-processed $2 \%$ fat chocolate milk, and low-fat strawberry yogurt on the sensory characteristics and stability of vitamin D during processing and storage.

\section{MATERIALS AND METHODS}

\section{Manufacturing Procedures}

HTST-Processed 2\% Fat Milk Preparation. Three $54.5-\mathrm{kg}$ batches of $2 \%$ fat milk were prepared by standardizing raw skim with raw cream. One batch was the control treatment and was not fortified with vitamin D. One batch was used to prepare the $100 \mathrm{IU} /$ serving $(240 \mathrm{~mL})$ treatment, and one batch was used to prepare the $250 \mathrm{IU} /$ serving $(240 \mathrm{~mL})$ treatment. Both of the vitamin D treatments were fortified with dry, water-dispersible vitamin D concentrate (vitamin D3 type CWS, 100,000 IU/g, DSM Nutritional Products, Parsippany, NJ). For the $100 \mathrm{IU} /$ serving treatment, the vitamin D concentrate was used to prepare an initial dilution containing $2.2 \mathrm{~g}$ of vitamin D supplement and $97.8 \mathrm{~g}$ of distilled water, whereas for the $250 \mathrm{IU} /$ serving treatment, the vitamin $\mathrm{D}$ supplement was used to prepare an initial dilution contain $5.5 \mathrm{~g}$ of vitamin D supplement and $94.5 \mathrm{~g}$ of distilled water. A $10.5-\mathrm{g}$ aliquot of each respective dilution was added to $54.5 \mathrm{~kg}$ of standardized milk (skim and cream) to obtain the 100 $\mathrm{IU} /$ serving and $250 \mathrm{IU} /$ serving treatments. After being thoroughly mixed, the 3 treatments were homogenized $(13.8 / 3.4 \mathrm{MPa})$, pasteurized at $73^{\circ} \mathrm{C}$ for $15 \mathrm{~s}$ using a plate heat exchanger (Super Plate, Cherry-Burrell Corp., Chicago, IL), packaged in half-gallon opaque plastic containers, and stored for $21 \mathrm{~d}$ at $4^{\circ} \mathrm{C}$. All 3 
batches were prepared in triplicate using 3 different lots of raw skim and raw cream. Samples of the milk were collected from each treatment before pasteurization and at 0,14 , and $21 \mathrm{~d}$ of storage. Each sample was analyzed for vitamin $\mathrm{D}$ in duplicate by Silliker Laboratories (Chicago Heights, IL) using an HPLC-based method (Reynolds and Judd, 1984). The fat, protein, and total solids content of each sample after pasteurization were determined by using an infrared analyzer (FT120, Foss North America, Minneapolis, MN).

UHT-Processed 2\% Fat Chocolate Milk Preparation. Three $34.9-\mathrm{kg}$ batches of $2 \%$ fat chocolate milk were prepared by first standardizing raw skim with raw cream to obtain three $32.7-\mathrm{kg}$ batches of $2.15 \%$ fat milk. Subsequently, $0.39 \mathrm{~kg}$ of cocoa powder (Main Street Ingredients, La Crosse, WI), $1.64 \mathrm{~kg}$ of sugar (American Crystal, Moorhead, MN), $164 \mathrm{~g}$ of carrageenan (TIC Gums, Belcamp, MD), and $20 \mathrm{~g}$ of vanilla (Robertet Flavors, Piscataway, NJ) were added to each batch of standardized milk. After addition of all ingredients, each batch was thoroughly mixed. One batch served as the control and was not fortified with vitamin D. One batch was the $100 \mathrm{IU} /$ serving $(240 \mathrm{~mL})$ treatment and was fortified with dry, water-dispersible vitamin D concentrate (Vitamin D3 type CWS, 100,000 $\mathrm{IU} / \mathrm{g}$, DSM Nutritional Products). For this treatment, the vitamin D supplement was used to prepare an initial dilution containing $1.41 \mathrm{~g}$ of vitamin $\mathrm{D}$ supplement and $98.59 \mathrm{~g}$ of distilled water. A 10.5-g aliquot of the dilution was added to the $2 \%$ fat chocolate milk. One batch was the $250 \mathrm{IU} /$ serving $(240 \mathrm{~mL})$ treatment and was also fortified with dry, water-dispersible vitamin D supplement (vitamin D3 type CWS, 100,000 IU/g, DSM Nutritional Products). For this treatment, the vitamin D supplement was used to prepare an initial dilution containing $3.52 \mathrm{~g}$ of vitamin D supplement and 96.48 $\mathrm{g}$ of distilled water. A 10.5-g aliquot of the dilution was added to the $2 \%$ fat chocolate milk. After being thoroughly mixed, the 3 treatments were UHT pasteurized at $138^{\circ} \mathrm{C}$ for $2 \mathrm{~s}$ and homogenized (13.8/3.4 MPa) using a laboratory-scale MicroThermics UHT processing unit (MicroThermics Inc., Raleigh, NC), aseptically packaged into sterilized opaque plastic containers, and stored at $4^{\circ} \mathrm{C}$. All 3 batches were prepared in triplicate using 3 different lots of raw skim and raw cream. Samples of the chocolate milk were collected from each treatment before UHT processing and at 0,40 , and 60 d of storage. Each sample was analyzed for vitamin D in duplicate by Silliker Laboratories using an HPLCbased method (Reynolds and Judd, 1984). The fat and total protein of each sample after pasteurization were determined by Mojonnier and Kjeldahl total nitrogen analysis, respectively (Wehr and Frank, 2004).
Low-Fat Strawberry Yogurt Product Preparation. Initially, three $15.45-\mathrm{kg}$ batches of yogurt base were prepared by combining $14.13 \mathrm{~kg}$ of $1.8 \%$ fat raw milk, $0.77 \mathrm{~kg}$ of nonfat dry milk (Plainview Milk Products, Plainview, MN), $0.42 \mathrm{~kg}$ of sugar (American Crystal), $88 \mathrm{~g}$ of gelatin (Continental Colloids, West Chicago, IL), and $34 \mathrm{~g}$ of modified corn starch (National Starch, Bridgewater, NJ). One batch served as the control and was not fortified with vitamin D. One batch was the $100 \mathrm{IU} /$ serving $(227 \mathrm{~g})$ treatment and was fortified with dry, water-dispersible vitamin D supplement (Vitamin D3 type CWS, 100,000 IU/g, DSM Nutritional Products). For this treatment, an initial dilution was prepared using $0.80 \mathrm{~g}$ of vitamin D supplement and $99.2 \mathrm{~g}$ of distilled water. A 10.5-g aliquot of the dilution was added to the yogurt base. One batch was the $250 \mathrm{IU} /$ serving (227 g) treatment and was also fortified with dry, water-dispersible vitamin D supplement (vitamin D3 type CWS, 100,000 IU/g, DSM Nutritional Products). For this treatment, an initial dilution was prepared using $2.0 \mathrm{~g}$ of vitamin D supplement and $98 \mathrm{~g}$ of distilled water. A 10.5-g aliquot of the dilution was added to the yogurt base. After being thoroughly mixed, each yogurt base was heated to $85^{\circ} \mathrm{C}$ for $30 \mathrm{~min}$, cooled to $54^{\circ} \mathrm{C}$, homogenized $(13.8 / 3.4$ $\mathrm{MPa}$ ), cooled to $43^{\circ} \mathrm{C}$, and inoculated with $2.1 \mathrm{~g}$ of direct vat set culture (Lactobacillus delbrueckii ssp. bulgaricus and Streptococcus thermophilus, Danisco USA, Madison, WI). Each yogurt base was incubated at $43^{\circ} \mathrm{C}$ until a $\mathrm{pH}$ of 4.6 was reached. After reaching $\mathrm{pH} 4.6$, each yogurt base was transferred to a cooler $\left(4^{\circ} \mathrm{C}\right)$ and stored overnight. Finally, each 18.18-kg batch of yogurt was prepared by mixing $15.45 \mathrm{~kg}$ of fermented yogurt base with $2.73 \mathrm{~kg}$ of strawberry puree (Denali Ingredients, New Berlin, WI). The final product was packaged into $250-\mathrm{g}$ plastic containers and stored at $4^{\circ} \mathrm{C}$. All 3 batches were prepared in triplicate using 3 different lots of raw milk. Samples of the final yogurt were collected at 0,28 , and $42 \mathrm{~d}$ of storage. Each sample was analyzed for vitamin D in duplicate by Silliker Laboratories using an HPLC-based method (Reynolds and Judd, 1984). The fat and total protein of each yogurt were determined by Mojonnier and Kjeldahl total nitrogen analysis, respectively (Wehr and Frank, 2004).

\section{Statistical Analysis}

A $3 \times 3$ randomized complete block design was used for the HTST-processed $2 \%$ fat milk, UHT-processed $2 \%$ fat chocolate milk, and low-fat strawberry yogurt studies. In each study the 3 treatments (control, 100 $\mathrm{IU}$ vitamin $\mathrm{D}$ per serving, and $250 \mathrm{IU}$ vitamin $\mathrm{D}$ per serving) were made from the same standardized milk 
Table 1. Vitamin D content (mean of 3 replicates) of HTST-processed $2 \%$ fat milk during $21 \mathrm{~d}$ of storage at $4^{\circ} \mathrm{C}$

\begin{tabular}{|c|c|c|c|c|c|c|}
\hline Treatment & \multicolumn{2}{|c|}{ Day 0} & \multicolumn{2}{|c|}{ Day 14} & \multicolumn{2}{|c|}{ Day 21} \\
\hline Control & $<10$ & - & $<10$ & - & $<10$ & - \\
\hline $250 \mathrm{IU}^{1} /$ serving & 275 & 2.65 & 281 & 7.57 & 279 & 3.00 \\
\hline
\end{tabular}

${ }^{1}$ Values reported as international units (IU) of vitamin D per serving.

and were replicated 3 times using different lots of milk. Storage stability of vitamin D in each product was analyzed using a repeated measures design. Analysis of variance was performed to obtain the mean squares and $P$-values using SAS software (SAS Institute, 1990). All data were analyzed at a significance level of 0.05 .

\section{Sensory Analysis}

A replicated triangle test was performed using a panel of 30 to 35 judges at the Sensory Center (Department of Food Science and Nutrition, University of Minnesota) to detect differences in the overall sensory attributes of the control and vitamin D-fortified HTSTprocessed $2 \%$ fat milk samples after $14 \mathrm{~d}$ of refrigerated storage. Each judge received 2 triangle tests. In one test, the fortified milk (100 IU) was the odd sample. In the other test, the control was the odd sample. This was also done for the $250 \mathrm{IU}$ versus control and $100 \mathrm{IU}$ versus 250 IU milks. Each judge was asked to identify the odd sample. The nature of the odd sample and the order of samples in each set were balanced. Normal distribution, as an approximation for binomial distribution, was used for data analysis (Lawless and Heymann, 1998). The chance probability of getting both triangle tests correct was $1 / 9$. Statistics were performed at a 0.05 significance level. The same procedures were used for the UHT-processed $2 \%$ fat chocolate milk and the low-fat strawberry yogurt. All samples were stored at $4^{\circ} \mathrm{C}$ before analysis. Sensory analysis was conducted after $40 \mathrm{~d}$ of refrigerated storage for the $2 \%$ fat chocolate milk and after $28 \mathrm{~d}$ for the low-fat strawberry yogurt. Triangle tests for each product were replicated for the 3 batches of HTST-processed $2 \%$ fat milk, UHT-processed $2 \%$ fat chocolate milk, and low-fat strawberry yogurt.

\section{RESULTS AND DISCUSSION}

\section{HTST-Processed 2\% Fat Milk}

There were no significant $(P>0.05)$ differences among the treatments in the composition of the HTSTprocessed $2 \%$ fat milk. The mean fat, protein, and total solids contents among the treatments ranged from 1.96 to $2.06 \%, 3.09$ to $3.10 \%$, and 10.54 to $10.57 \%$, respectively. There were no significant $(P>0.05)$ differences in the vitamin $\mathrm{D}$ content of the $100 \mathrm{IU}$ treatment (108 $\mathrm{IU} /$ serving before processing and $110 \mathrm{IU} /$ serving after processing) or the $250 \mathrm{IU}$ treatments $(276 \mathrm{IU} /$ serving before processing and $275 \mathrm{IU} /$ serving after processing) before and after processing. The mean vitamin $\mathrm{D}$ results of the 3 replicates of HTST-processed $2 \%$ fat milk at 0,14 , and $21 \mathrm{~d}$ of refrigerated storage are shown in Table 1. The level of vitamin $\mathrm{D}$ in each treatment at 0 d of storage was close to the targeted levels of fortification (100 and $250 \mathrm{IU} /$ serving). Additionally, there was no significant $(P>0.05)$ change in vitamin $\mathrm{D}$ during the 21-d storage period. These results demonstrate that an increase in vitamin D fortification from 100 to 250 $\mathrm{IU} /$ serving does not affect vitamin D stability during processing and storage over the typical shelf life $(21 \mathrm{~d})$ at either fortification level (100 or $250 \mathrm{IU}$ ) in HTSTprocessed $2 \%$ fat milk. Previous studies have also determined that vitamin D is not affected by HTST processing (Wagner et al., 2008) and that it is stable during storage at $4^{\circ} \mathrm{C}$ (Renken and Warthesen, 1993).

The results for the sensory analysis (triangle test) of the 3 replicates of HTST-processed $2 \%$ fat milk conducted at $14 \mathrm{~d}$ of storage are shown in Table 2. There was no significant $(P>0.05)$ difference between any treatments in all 3 replicates. These results demonstrate

Table 2. Sensory analysis (triangle test) of HTST-processed $2 \%$ milk at $14 \mathrm{~d}$ of refrigerated storage at $4^{\circ} \mathrm{C}$

\begin{tabular}{|c|c|c|c|c|c|c|c|c|c|}
\hline \multirow[b]{2}{*}{ Replicate } & \multicolumn{3}{|c|}{ Control vs. $100 \mathrm{IU}$} & \multicolumn{3}{|c|}{ Control vs. $250 \mathrm{IU}$} & \multicolumn{3}{|c|}{$100 \mathrm{IU}$ vs. $250 \mathrm{IU}$} \\
\hline & No. correct $^{1}$ & Z-score & $P$-value & No. correct & Z-score & $P$-value & No. correct & Z-score & $P$-value \\
\hline 2 & 2 & -1.07 & 0.87 & 5 & 0.68 & 0.25 & 6 & 1.26 & 0.19 \\
\hline 3 & 3 & -2.23 & 1.00 & 5 & 0.68 & 0.23 & 4 & 0.10 & 0.42 \\
\hline
\end{tabular}

${ }^{1}$ Indicates number of judges correctly selecting the odd sample in both triangle tests; 30 judges were used in all replicates. 
Table 3. Vitamin D content (mean of 3 replicates) of UHT-processed $2 \%$ fat chocolate milk during $60 \mathrm{~d}$ of storage at $4^{\circ} \mathrm{C}$

\begin{tabular}{|c|c|c|c|c|c|c|}
\hline Treatment & \multicolumn{2}{|c|}{ Day 0} & \multicolumn{2}{|c|}{ Day 40} & \multicolumn{2}{|c|}{ Day 60} \\
\hline Control & $<10$ & - & $<10$ & - & $<10$ & - \\
\hline $250 \mathrm{IU}^{1} /$ serving & 265 & 19.97 & 254 & 24.42 & 251 & 9.61 \\
\hline
\end{tabular}

${ }^{1}$ Values reported as international units (IU) of vitamin D per serving.

that fortification of HTST-processed $2 \%$ fat milk with vitamin $\mathrm{D}$, irrespective of the fortification level (100 or $250 \mathrm{IU} /$ serving), will not result in a change in the sensory characteristics.

\section{UHT-Processed 2\% Fat Chocolate Milk}

There were no significant $(P>0.05)$ differences among the treatments in the composition of the UHTprocessed $2 \%$ fat chocolate milk. The mean fat and protein contents among the treatments ranged from 2.04 to $2.06 \%$ and from 3.33 to $3.38 \%$, respectively. There were no significant $(P>0.05)$ differences in the vitamin $\mathrm{D}$ content of the $100 \mathrm{IU}$ treatment (109 IU/serving before processing and $106 \mathrm{IU} /$ serving after processing) or the $250 \mathrm{IU}$ treatments $(257 \mathrm{IU} /$ serving before processing and $264 \mathrm{IU} /$ serving after processing) before and after processing. The mean vitamin $\mathrm{D}$ results for the 3 replicates of UHT-processed $2 \%$ fat chocolate milk at 0 , 40, and $60 \mathrm{~d}$ of refrigerated storage are shown in Table 3. The level of vitamin $\mathrm{D}$ in each treatment at $0 \mathrm{~d}$ of storage was close to the targeted levels of fortification (100 and $250 \mathrm{IU}$ ). Additionally, there was no significant $(P>0.05)$ change in the level of vitamin $\mathrm{D}$ during the $60-\mathrm{d}$ storage period. These results demonstrate that an increase in vitamin $\mathrm{D}$ fortification from 100 to $250 \mathrm{IU} /$ serving does not affect vitamin D stability during processing, and storage over the typical shelf life $(60 \mathrm{~d})$ at either fortification level (100 or $250 \mathrm{IU})$ in UHT-processed $2 \%$ fat chocolate milk. The stability of vitamin $\mathrm{D}$ to UHT processing is not surprising because vitamin $\mathrm{D}$ in milk has been reported to be stable to sterilization (Hartman and Dryden, 1974).
The results for the sensory analysis (triangle test) of the 3 replicates of UHT $2 \%$ fat chocolate milk conducted at $40 \mathrm{~d}$ of storage are shown in Table 4 . There were no significant $(P>0.05)$ differences between any treatments in all 3 replicates. These results demonstrate that fortification of UHT-processed $2 \%$ fat chocolate milk with vitamin $\mathrm{D}$, irrespective of the fortification level (100 or $250 \mathrm{IU} /$ serving), will not result in a change in the sensory characteristics.

\section{Low-Fat Strawberry Yogurt}

There were no significant $(P>0.05)$ differences among the treatments in the composition of the low-fat strawberry yogurt. The mean fat and protein contents among the treatments ranged from 1.38 to $1.42 \%$ and from 4.55 to $4.65 \%$, respectively. The mean vitamin $\mathrm{D}$ results of the 3 replicates of low-fat strawberry yogurt at 0,28 , and $42 \mathrm{~d}$ of refrigerated storage are shown in Table 5. The level of vitamin $\mathrm{D}$ in each treatment at $0 \mathrm{~d}$ of storage was slightly higher than the targeted levels of fortification (100 and $250 \mathrm{IU})$. There was no significant $(P>0.05)$ change in vitamin $\mathrm{D}$ during the 42-d storage period. These results demonstrate that vitamin D fortification at 100 or $250 \mathrm{IU} /$ serving is stable over the typical shelf life (42 d) of low-fat strawberry yogurt. Previous research has also found that vitamin $\mathrm{D}$ was unaffected by yogurt fermentation and that it was stable during storage at $4^{\circ} \mathrm{C}$ (Kazmi et al., 2007).

The results for the sensory analysis (triangle test) of the 3 replicates of low-fat strawberry yogurt conducted at $28 \mathrm{~d}$ of storage are shown in Table 6 . In all 3 replicates there was no significant $(P>0.05)$ difference

Table 4. Sensory analysis (triangle test) of UHT-processed $2 \%$ chocolate milk at $40 \mathrm{~d}$ of refrigerated storage at $4^{\circ} \mathrm{C}$

\begin{tabular}{|c|c|c|c|c|c|c|c|c|c|}
\hline Replicate & \multicolumn{3}{|c|}{ Control vs. $100 \mathrm{IU}$} & \multicolumn{3}{|c|}{ Control vs. $250 \mathrm{IU}$} & \multicolumn{3}{|c|}{$100 \mathrm{IU}$ vs. $250 \mathrm{IU}$} \\
\hline 1 & 3 & -0.48 & 0.74 & 4 & 0.10 & 0.52 & 7 & 1.84 & 0.07 \\
\hline 3 & 5 & 0.60 & 0.25 & 5 & 0.60 & 0.25 & 2 & -1.11 & 0.87 \\
\hline
\end{tabular}

${ }^{1}$ Indicates number of judges correctly selecting the odd sample in both triangle tests; 34,31 , and 31 judges were used in replicates 1 , 2, and 3 , respectively. 
Table 5. Vitamin D content (mean of 3 replicates) of low-fat strawberry yogurt during $42 \mathrm{~d}$ of storage at $4^{\circ} \mathrm{C}$

\begin{tabular}{|c|c|c|c|c|c|c|}
\hline Treatment & \multicolumn{2}{|c|}{ Day 0} & \multicolumn{2}{|c|}{ Day 28} & \multicolumn{2}{|c|}{ Day 42} \\
\hline Control & $<10$ & - & $<10$ & - & $<10$ & - \\
\hline $250 \mathrm{IU}^{1} /$ serving & 287 & 32.72 & 298 & 25.42 & 294 & 22.48 \\
\hline
\end{tabular}

${ }^{1}$ Values reported as international units (IU) of vitamin D per serving.

Table 6. Sensory analysis (triangle test) of low-fat strawberry yogurt at $28 \mathrm{~d}$ of refrigerated storage at $4^{\circ} \mathrm{C}$

\begin{tabular}{|c|c|c|c|c|c|c|c|c|c|}
\hline Replicate & \multicolumn{3}{|c|}{ Control vs. $100 \mathrm{IU}$} & \multicolumn{3}{|c|}{ Control vs. $250 \mathrm{IU}$} & \multicolumn{3}{|c|}{$100 \mathrm{IU}$ vs. $250 \mathrm{IU}$} \\
\hline 2 & 6 & 1.02 & 0.15 & 5 & 0.46 & 0.29 & 4 & -0.09 & 0.50 \\
\hline 3 & 6 & 1.17 & 0.12 & 1 & -1.68 & 0.97 & 5 & 0.60 & 0.25 \\
\hline
\end{tabular}

${ }^{1}$ Indicates number of judges correctly selecting the odd sample in both triangle tests; 30,33 , and 31 judges were used in replicates 1,2 , and 3 , respectively.

between the control treatment and the $250 \mathrm{IU}$ treatment, or between the $100 \mathrm{IU}$ treatment and the $250 \mathrm{IU}$ treatment. In one replicate, the sensory panel detected a significant $(P<0.05)$ difference between the control and the $100 \mathrm{IU}$ treatment. This significant difference appears to be unrelated to vitamin D fortification because there were no significant differences between the other 2 replicates or between the control and 250 IU in any replicate. We speculate that this significant difference may have been related to the yogurt processing conditions of this treatment because minor changes in fermentation characteristics or the extent of stirring before packaging can have an effect on yogurt texture, which may have been detected by the sensory panel. These results demonstrate that fortification of low-fat strawberry yogurt with vitamin $\mathrm{D}$, irrespective of the fortification level (100 or $250 \mathrm{IU} /$ serving), will not result in a change in the sensory characteristics.

\section{Verification of Accurate Fortification}

Although this study and previous research studies have found that vitamin D is stable in milk and dairy products during processing and storage, in the early 1990s Holick et al. (1992) reported that only $29 \%$ of commercial milk samples fortified with vitamin D had measured concentrations of vitamin $\mathrm{D}$ that were within 80 to $120 \%$ of the label claim. Since the early 1990 s, the Pasteurized Milk Ordinance has been revised to require each manufacturer to conduct annual testing of milk products for vitamin D level by a FDA-certified laboratory. This change in the Pasteurized Milk Ordinance appears to have resulted in improved label compliance: in a recent USDA study, $77 \%$ of milk products tested were very close to or within the labeled level of vitamin D (Holden et al., 2009). These studies highlight the importance of verification of proper fortification of vitamin D. Consequently, if the vitamin D fortification level of dairy products is increased from 100 to $250 \mathrm{IU} /$ serving, verification of proper fortification is warranted.

\section{CONCLUSIONS}

Vitamin D fortification at $250 \mathrm{IU} /$ serving was stable over the shelf lives of HTST-processed $2 \%$ fat milk, UHT-processed $2 \%$ fat chocolate milk, and low-fat strawberry yogurt. No effect on the sensory characteristics of these products was found by increasing vitamin D fortification from 100 to $250 \mathrm{IU} /$ serving. These results demonstrate that a feasible strategy to increase vitamin D supplementation is to increase the fortification level of milk from 100 to $250 \mathrm{IU} /$ serving as well as increase the range of dairy products fortified with vitamin D.

\section{ACKNOWLEDGMENTS}

We thank Dairy Management Inc. (Rosemont, IL) and Midwest Dairy Association (St. Paul, MN) for financial support.

\section{REFERENCES}

Brannon, P. M., E. A. Yetley, R. L. Bailey, and M. F. Picciano. 2008. Overview of conference "Vitamin D and Health in the 21st Century: An Update" . Am. J. Clin. Nutr. 88(Suppl.):483S-490S. Calvo, M. S., and S. J. Whiting. 2003. Prevalence of vitamin D insufficiency in Canada and the United States: Importance to 
health status and efficacy of current food fortification and dietary supplement use. Nutr. Rev. 61:107-113.

FDA. 2007. Appendix O. Vitamin fortification of fluid milk products. Pages 336-340 in Grade "A" Pasteurized Milk Ordinance. US Department of Health and Human Services, Washington, DC.

Hartman, A. M., and L. P. Dryden. 1974. Vitamins in milk and milk products. Pages 325-401 in Fundamental of Dairy Chemistry. 2nd ed. B. H. Webb, A. H. Johnson, and J. A. Alford, ed. AVI/Van Norstrand Reinhold, New York, NY.

Heaney, R. P., K. M. Davies, T. C. Chen, M. F. Holick, and M. J. Barger-Lux. 2003. Human serum 25-hydroxycholecalciferol response to extended oral dosing with cholecalciferol. Am. J. Clin. Nutr. 77:204-210.

Holden, J. M., K. Y. Patterson, J. Exler, R. L. Horst, L. E. Lemar, and K. M. Phillips. 2009. Vitamin D3 content of fortified yogurt and milk as determined by the USDA National Food and Nutrient Analysis Program. FASEB J. 23:112.8.

Holick, M. F. 1994. McCollum Award Lecture: Vitamin D: New horizons for the 21st century. Am. J. Clin. Nutr. 60:619-630.

Holick, M. F. 2002. Vitamin D, The underappreciated D-lightful hormone that is important for skeletal and cellular health. Curr. Opin. Endocrinol. Diabetes 9:87-98.

Holick, M. F. 2007. Vitamin D deficiency. N. Engl. J. Med. 357:266281

Holick, M. F., Q. Shao, W. W. Liu, and T. C. Chen. 1992. The vitamin D content of fortified milk and infant formula. N. Engl. J. Med. 326:1173-1177.

Hollis, B. W. 2005. Circulating 25-hydroxyvitamin D levels indicative of vitamin D sufficiency: Implications for establishing a new effective dietary intake recommendation for vitamin D. J. Nutr. 135:317-322.

International Dairy Foods Association. 2008. Dairy Facts. IDFA, Washington, DC.

Kazmi, S. A., R. Vieth, and D. Rousseau. 2007. Vitamin D $_{3}$ fortification and quantification in processed dairy products. Int. Dairy J. $17: 753-759$.

Ladizesky, M., Z. Lu, B. Oliver, N. San Roman, S. Diaz, M. F. Holick, and C. Mautalen. 1995. Solar ultraviolet B radiation and photoproduction of vitamin $\mathrm{D}_{3}$ in central and southern areas of Argentina. J. Bone Miner. Res. 10:545-549.
Lawless, H. T., and H. Heymann. 1998. Appendix II. Nonparameter and binomial-based statistical methods. Pages 679-699 in Sensory Evaluation of Food: Principles and Practices. Chapman \& Hall, New York, NY.

National Academy of Sciences. 1997. Dietary Reference Intakes for Calcium, Phosphorus, Magnesium, Vitamin D and Fluoride. National Academy of Sciences, Institute of Medicine, Food and Nutrition Board. National Academy Press, Washington, DC.

Park, E. A. 1940. The therapy of rickets. J. Am. Med. Assoc. 115:370379.

Renken. S. A., and J. J. Warthesen. 1993. Vitamin D stability in milk. J. Food Sci. 58:552-555.

Reynolds, S. L., and H. J. Judd. 1984. Rapid procedure for the determination of vitamins A and D in fortified skim milk powder using high performance liquid chromatography. Analyst (Lond.) 109:489-492.

SAS Institute. 1990. SAS User's Guide: Statistics. Version 6 ed. SAS Inst. Inc., Cary, NC.

Thomas, M. K., D. M. Lloyd-Jones, R. I. Thadani, A. C. Shaw, D. J. Deraska, B. T. Kitch, E. C. Vamvakas, I. M. Dick, R. L. Prince, and J. S. Finkelstein. 1998. Hypovitaminosis D in medical inpatients. N. Engl. J. Med. 338:777-783.

Upreti, P., V. V. Mistry, and J. J. Warthesen. 2002. Estimation and fortification of Vitamin $\mathrm{D}_{3}$ in pasteurized process cheese. J. Dairy Sci. 85:3173-3181.

Vieth, R. 1999. Vitamin D supplementation, 25-hydroxyvitamin D concentrations, and safety. Am. J. Clin. Nutr. 69:842-856.

Wagner, D., D. Rousseau, G. Sidhom, M. Pouliot, P. Audet, and R. Vieth. 2008. Vitamin $\mathrm{D}_{3}$ fortification, quantification, and longterm stability in Cheddar and low-fat cheeses. J. Agric. Food Chem. 56:7964-7969.

Webb, A. R., L. Kline, and M. F. Holick. 1988. Influence of season and latitude on cutaneous synthesis of vitamin $D_{3}$ : Exposure to winter sunlight in Boston and Edmonton will not promote vitamin $\mathrm{D}_{3}$ synthesis in human skin. J. Clin. Endocrinol. Metab. 67:373378

Wehr, H. M., and J. E. Frank. 2004. Standard Methods for the Examination of Dairy Products. 17th ed. American Public Health Association, Washington, DC. 